\title{
Variation in residual feed intake in Holstein-Friesian dairy heifers in southern Australia
}

\author{
Y. J. Williams, ${ }^{\star 1}$ J. E. Pryce,† C. Grainger,ł W. J. Wales,‡ N. Linden,§ M. Porker,§ and B. J. Hayes† \\ *Department of Primary Industries, Tatura Centre, 255 Ferguson Rd., Tatura, Victoria, Australia 3616 \\ †Department of Primary Industries, Victorian AgriBiosciences Centre, 1 Park Dve., Bundoora, Victoria, 3083 Australia \\ ‡Department of Primary Industries, Ellinbank Centre, 1301 Hazeldean Rd., Ellinbank, Victoria, 3820 Australia \\ $\S$ Department of Primary Industries, Rutherglen Centre, RMB 1145 Chiltern Valley Rd., Rutherglen, Victoria, 3685 Australia
}

\section{ABSTRACT}

Feed conversion efficiency of dairy cattle is an important component of the profitability of dairying, given that the cost of feed accounts for much of total farm expenses. Residual feed intake (RFI) is a useful measure of feed conversion efficiency, as it can be used to compare individuals with the same or differing levels of production during the period of measurement. If genetic variation exists in RFI among dairy cattle, selection for lower RFI could improve profitability. In this experiment, RFI was defined as the difference between an animal's actual feed intake and its expected feed intake, which was determined by regression of dry matter (DM) intake against mean body weight (BW) and growth rate. Nine hundred and three Holstein-Friesian heifer calves, aged between 5 and 7 mo, were measured for RFI in 3 cohorts of approximately 300 animals. Calves were housed under feedlot style conditions in groups of 15 to 20 for 85 to $95 \mathrm{~d}$ and had ad libitum access to a cubed alfalfa hay. Intakes of individual animals were recorded via an electronic feed recording system and BW gain was determined by weighing animals once or twice weekly, over a period of 60 to $70 \mathrm{~d}$. Calves had $\mathrm{DM}$ intake (mean $\pm \mathrm{SD}$ ) of $8.3 \pm 1.37 \mathrm{~kg}$ of $\mathrm{DM} / \mathrm{d}$ over the measurement period with BW gains of $1.1 \pm 0.17$ $\mathrm{kg} / \mathrm{d}$. In terms of converting feed energy for maintenance and growth, the $10 \%$ most efficient calves (lowest RFI) ate $1.7 \mathrm{~kg}$ of DM less each day than the $10 \%$ least efficient calves (highest RFI) for the same rate of growth. Low-RFI heifers also had a significantly lower rate of intake $(\mathrm{g} / \mathrm{min})$ than high-RFI heifers. The heritability estimate of RFI (mean $\pm \mathrm{SE})$ was $0.27( \pm 0.12)$. These results indicate that substantial genetic variation in RFI exists, and that the magnitude of this variation is large enough to enable this trait to be considered as a candidate trait for future dairy breeding goals. A primary focus of future research should be to ensure

Received November 17, 2010.

Accepted May 13, 2011.

${ }^{1}$ Corresponding author: Yvette.Williams@dpi.vic.gov.au that calves that are efficient at converting feed energy for maintenance and growth also become efficient at converting feed energy to milk. Future research will also be necessary to identify the consequences of selection for RFI on other traits (especially fertility and other fitness traits) and if any interactions exist between RFI and feeding level.

Key words: feed conversion efficiency, residual feed intake, dairy heifer, heritability

\section{INTRODUCTION}

As with most animal production systems, the cost of feed in a dairy production system is a high proportion of the total farming expenses. Case studies on a range of dairy farm types in southern Australia show feed costs are 43 to $67 \%$ of total costs (Ho et al., 2005). Efficient use of feed for milk production is, therefore, essential for maintaining a profitable operation (Beever and Doyle, 2007) and efficiency of the cow plays an important part in this. An additional benefit of more efficient cattle is lower methane emissions (Hegarty et al., 2007), which could have implications for mitigation of greenhouse gases (Wall et al., 2010).

Feeding efficiency in cows may be evaluated in several ways. The most common is as gross feed efficiency, which is defined as the net output per unit of feed eaten. For growing animals the output is weight gain and for lactating cows the output is milk production. Gross efficiency of Australian dairy cattle is measured by the Australian Profit Ranking index. This index includes BW with an economic weight derived from an economic model that includes energetic requirements for maintenance and production (Pryce et al., 2009). But, it is conventionally assumed that the partial efficiencies in these pathways are fixed (i.e., no variation between animals exists; Veerkamp and Emmans, 1995) and, therefore, that maintenance requirements are directly proportional to metabolic body weight $\left(\mathrm{BW}^{0.75}\right)$. It also assumes that maintenance is not correlated with yield or genetic merit for yield across cows and that the partial efficiency of converting feed energy into 
milk energy is constant across cows and across yield levels within a cow (Veerkamp and Emmans, 1995). As a result, gross efficiency is phenotypically correlated with production, with the energy cost of maintenance diluted across more output units as production increases, so it cannot be used to compare between animals with differing levels of production. Additionally, gross efficiency does not account for differences in tissue balance between cows and this is an important source of variation in gross efficiency in some stages of lactation (Veerkamp and Emmans, 1995).

A measure of feed efficiency that is independent of an animal's body size and production level and also considered to represent the inherent variation in basic metabolic processes that determine efficiency is residual feed intake (RFI; Koch et al., 1963). Residual feed intake attempts to apportion the total feed intake to those functions for which it is used and is usually defined as the difference between an animal's actual feed intake and its expected feed intake based on its size and growth over a specific period (Archer et al., 1999). The value of RFI for a particular animal reflects the difference in how that animal uses energy compared with the population mean - animals with a better-than-average metabolic efficiency require less feed than predicted.

An examination of feed efficiency in Australian beef cattle herds using RFI has demonstrated that genetic variation in RFI does exist and RFI is moderately heritable, with estimates ranging from 0.18 to 0.39 (Arthur et al., 2004). There have been similar findings in beef cattle internationally with differences in RFI of at least $5.5 \mathrm{~kg} / \mathrm{d}$ between the most efficient and least efficient animals under study (van der Westhuizen et al., 2004; Hoque et al., 2007; Nkrumah et al., 2007). The genetic variation demonstrated in beef cattle cannot be assumed, however, to be the same in dairy cattle for 2 reasons. First, dairy cattle have been subjected to very different selection pressures than beef cattle over a long period of time - especially for high milk production. Second, in lactating dairy cattle the calculation of RFI is complicated by the dynamic changes in BW and BCS that occur during the lactation cycle and which need to be accurately accounted for. As a result of this complexity, although RFI has been examined in lactating dairy cows, such studies have been conducted in small cohorts and so the amount of true genetic variation and its heritability have not been established (Van Arendonk et al.., 1991; Kennedy et al., 1993; Veerkamp et al., 1995). The challenge is that a large number of lactating cows must be tested to get accurate estimates of the genetic parameters. A simulation study carried out to determine the number of animals required to estimate the heritability of RFI showed that between 2,000 and 10,000 animals were needed to ensure the es- timate was close to the true value and the error around the estimate was small (McNaughton and Pryce, 2007). Unfortunately testing so many cows is likely to be both very expensive and logistically difficult. A possible alternative approach is to measure a large number of growing heifers for RFI, select the extremes and then confirm the ranking of these extreme animals for RFI in a lactating cow test. Measuring RFI in growing heifers, as opposed to lactating cows, is attractive, as the problems associated with negative energy balance due to mobilization of body tissue are limited. Although data on the relationship between energy balance in heifers and cows are scarce, it can be extrapolated from studies of reproductive performance in heifers. The generally better reproductive performance of heifers compared with lactating cows has largely been attributed to differences in energetic requirements due to lactation (Pryce et al., 2004). Some evidence also exists that selection for RFI in growing animals is correlated to RFI in mature animals (Nieuwhof et al., 1992) making it attractive to measure in nonlactating heifers as opposed to cows.

The aim of this experiment was to determine if measurable genetic variation in RFI exists among dairy heifers, by estimating the heritability for this trait. It was hypothesized that measurable genetic variation in RFI exists and that the heritability would be large enough to make genetic improvement of this trait feasible in dairy cattle.

\section{MATERIALS AND METHODS}

\section{Experimental Design}

The number of animals that were included in the experiment was based on 2 important factors: (1) the resources available to undertake the research and, (2) the number of animals required to estimate the true heritability of RFI. With a collaborative effort between research organizations in Australia and New Zealand, resources were available to take measurements required to calculate RFI on 2,000 calves, approximately 1,000 in each country. For the Australian component, 903 calves were screened in 3 cohorts over 1.5 yr (Table 1 ). Prior to the commencement of screening, all protocols were approved by the Victorian Department of Primary Industries (DPI) Agricultural Research and Extension Animal Ethics Committee.

\section{Testing Facility}

A testing facility was created at DPI-Rutherglen $\left(36^{\circ} 06^{\prime} \mathrm{S}, 146^{\circ} 30^{\prime} \mathrm{E}\right)$ by modifying an existing 20 pen feedlot that had previously been registered with the 
Table 1. Details (average \pm SD) of each cohort of calves tested for residual feed intake (RFI), the characteristics of feed offered, and the intakes, growth, and efficiencies measured

\begin{tabular}{|c|c|c|c|}
\hline \multirow[b]{2}{*}{ Item } & \multicolumn{3}{|c|}{ Cohort } \\
\hline & 1 & 2 & 3 \\
\hline Start of measurement period & March 2009 & September 2009 & March 2010 \\
\hline Number of calves & 297 & 302 & 304 \\
\hline Age $(\mathrm{d})$ & $220(16.9)$ & $188(20.3)$ & $220(19.4)$ \\
\hline BW (kg) & $224(38.3)$ & $179(35.4)$ & $210(40.1)$ \\
\hline Length of measurement period (d) & 70 & 61 & 60 \\
\hline Weighing frequency $(/ \mathrm{wk})$ & Once & Once and twice ${ }^{1}$ & Twice \\
\hline \multicolumn{4}{|l|}{ Feed characteristics } \\
\hline DM\% & 88.6 & 88.1 & 86.6 \\
\hline DM digestibility ( $\%$ of DM) & 65.2 & 65.7 & 67.9 \\
\hline $\mathrm{ME}(\mathrm{MJ}$ of $\mathrm{ME} / \mathrm{kg}$ of $\mathrm{DM})$ & 9.1 & 9.2 & 9.5 \\
\hline $\mathrm{CP}(\%$ of $\mathrm{DM})$ & 20.9 & 20.4 & 23.3 \\
\hline $\mathrm{NDF}(\%$ of DM) & 39.6 & 40.5 & 37.8 \\
\hline \multicolumn{4}{|l|}{ Intake, growth, and efficiency } \\
\hline DMI $(\mathrm{kg} / \mathrm{d})$ & $8.9(1.16)$ & $7.4(1.21)$ & $8.6(1.23)$ \\
\hline DMI $\Delta(\mathrm{kg} / \mathrm{d})$ & $0.02(0.021)$ & $0.06(0.014)$ & $0.03(0.016)$ \\
\hline Time spent in feeders $(\mathrm{min} / \mathrm{d})$ & $141(20)$ & $155(24)$ & $148(22)$ \\
\hline Intake rate $(\mathrm{g} / \mathrm{min})$ & $74(15)$ & $54(14)$ & $68(16)$ \\
\hline Growth rate $(\mathrm{kg} / \mathrm{d})$ & $1.0(0.15)$ & $1.1(0.14)$ & $1.2(0.15)$ \\
\hline $\mathrm{RFI}(\mathrm{kg}$ of $\mathrm{DM} / \mathrm{d})$ & $0.0(0.47)$ & $0.0(0.40)$ & $0.0(0.42)$ \\
\hline
\end{tabular}

${ }^{1}$ In cohort 2, calves were weighed twice weekly for the first 2 and last 2 wk of the measurement period, and once weekly for the middle $4 \mathrm{wk}$.

Australian Lot Feeders Association. Each pen measured $12.5 \times 25 \mathrm{~m}$ and had a gravel-type surface sloping away from a concrete apron at the front of the pen. In 17 of the pens, the original feeding bunkers were removed and 2 feed intake units per pen were installed on the concrete aprons. Each feed intake unit allowed one animal to access the feed at a time. All electronic and measuring devices in the feed intake units were made by Gallagher Animal Management Systems, Hamilton, New Zealand.

Feed intake units were hard-wired to data loggers, which polled each electronic identification reader and weight read out indicator every second to determine if an animal was present, its identification, and the weight of the feed bin at that particular time point. As such, the system continually recorded data $24 \mathrm{~h}$ per day for the duration of the trial.

\section{Animals, Management, and Feeding}

Holstein-Friesian heifer calves with 3 generations of known ancestry were sourced from 23 different farms, from northern Victoria, Australia. Calves in cohorts 1 and 3 were born in Spring (September and November) 2008 and 2009 and tested in Autumn (March to May) 2009 and 2010, respectively, whereas calves in cohort 2 were born in Autumn 2009 and then tested in Spring 2010 (Table 1). Prior to arriving at the testing facility, calves were managed according to the usual farm practices at their birth location.
Calves were penned in groups of 15 to 20 , by farm of origin where possible, for up to $95 \mathrm{~d}$. The space allowance varied from 16 to $21 \mathrm{~m}^{2}$ per animal and feed and water were continuously available to calves. The number of visits a calf could make daily to the feed intake units was not restricted and was limited only by the dynamics of the group of calves in the pen.

The first $22 \mathrm{~d}$ at the testing facility were an adjustment period to allow calves to adapt to the new environment and feeding conditions. A measurement period then ran for 60 to $70 \mathrm{~d}$ based on the optimum test duration recommendations of Archer et al. (1997) for measuring RFI. During this period, intake for each animal was recorded daily via the electronic feed recording system and calves were weighed 1 or 2 times per week on scales adjacent to the facility.

The duration of the measurement period was reduced by $10 \mathrm{~d}$ for cohorts 2 and 3 after analysis of the data from cohort 1 showed that the correlation between RFI calculated at d 56 and 70 was high (0.98; Figure 1a). Some re-ranking of animals at the extremes did occur and was believed to be driven by the lower correlation between 56- and 70-d BW gain (0.80; Figure 1b), showing how sensitive the BW gain calculation was when the number of measurements was increased from 8 to 10 . The correlation between DMI measured each day for 56 and $70 \mathrm{~d}$ was 0.995 and unlikely to contribute much to re-ranking of animals. To overcome the re-ranking issues, frequency of weighing was also increased for cohorts 2 and 3. A 10-d decrease in the measurement 

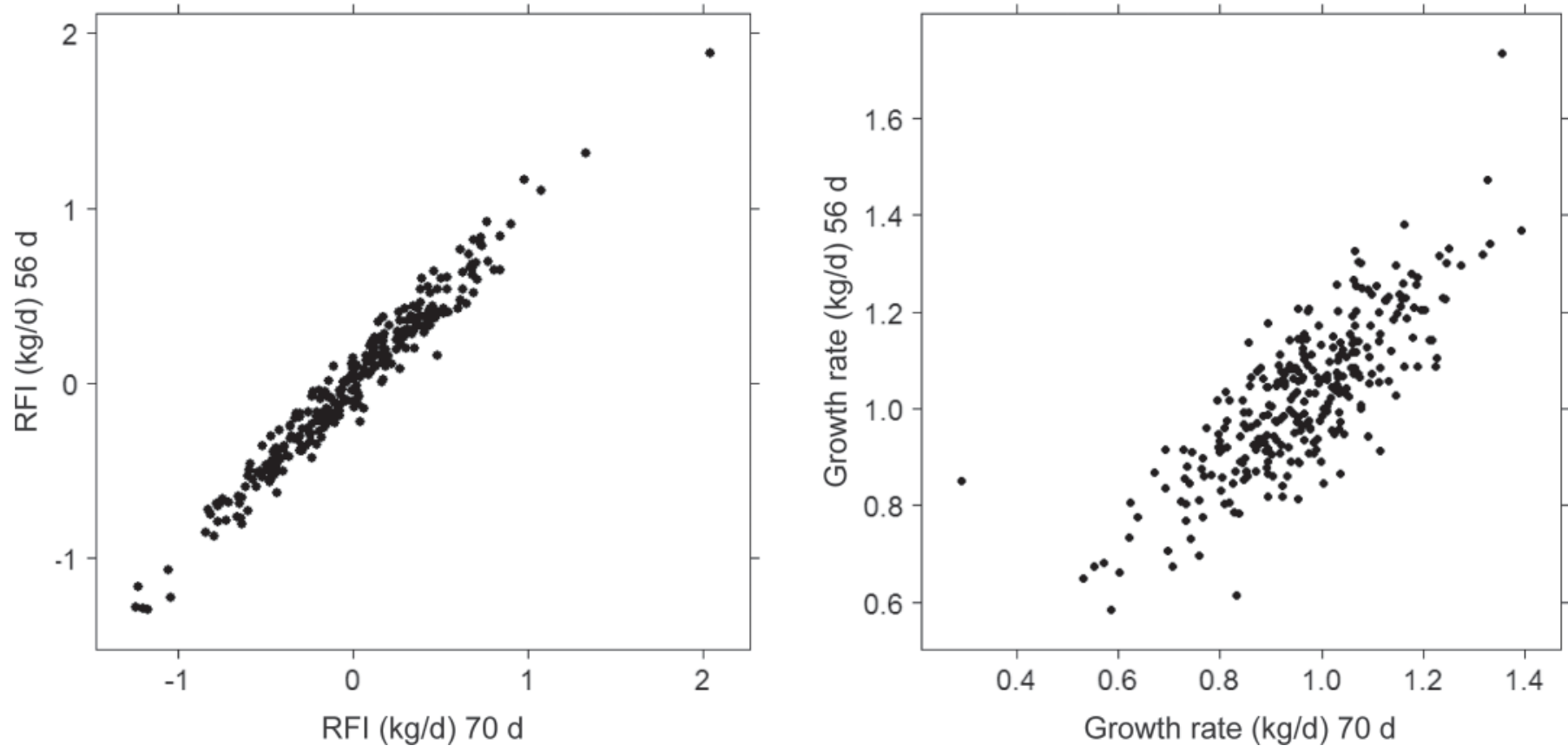

Figure 1. The effect of trial length (56 vs. 70 d) on (a) residual feed intake (RFI) and (b) growth rate for individual calves. The correlation for RFI was 0.98 and for growth rate, 0.80 .

period duration for cohorts 2 and 3 allowed substantial savings in feed costs.

During the testing period, calves ate alfalfa hay that had been pressed through a $32-\mathrm{mm}$ cubing dye. Feed bins were filled daily as required to ensure constant feed supply to calves. Samples of cubes fed to calves were collected each week, crushed, and a subsample dried at $100^{\circ} \mathrm{C}$ to determine DM content. A second subsample was dried at $60^{\circ} \mathrm{C}$ for $72 \mathrm{~h}$ and then ground through a 1-mm screen. Ground samples were analyzed by near infrared spectrometry (Feed Test/Agrifood Technology, Werribee, Victoria, Australia) for DM digestibility (DMD), and CP and NDF content. Metabolizable energy concentration was calculated as $\mathrm{ME}=(0.17 \times$ DMD) - 2 (Standing Committee on Agriculture, 1990). The nutritive characteristics of the alfalfa cubes are given in Table 1.

\section{Data Editing and Calculations}

Data Editing. Daily intake records were screened by plotting DMI for each day of the trial for individual heifers over the whole experiment, and by removing all points that yielded a residual that was numerically greater than 3 standard deviations of the intercept of the regression of DMI against day of trial. Deviant intake records accounted for only $0.003 \%$ of the observations.
A similar quality control measure was applied to the BW data except that the residual was calculated for the regression line (of BW against day of trial) instead of the intercept. The same rules applied to DMI for removal of deviant records were also used for BW data. None of the BW records, however, needed to be excluded from the data set.

Feeding event durations were summed to obtain total time spent feeding each day. Intake rate was calculated as daily intake/time spent feeding.

Data from 20 heifers that either died (6) during the experiment or were treated for illness (14) over a prolonged period were removed from the data set so that the final data set comprised 883 animals. Cohorts 1, 2, and 3 had 294, 287, and 302 heifers, respectively.

Calculation of Average DMI, BW, and Growth Rates for Individual Animals. In calves of the age used in this trial, growth is generally linear. Therefore, to calculate growth rates (BW $\Delta$ ) and midpoint BW for the measurement period, a linear regression of BW $(\mathrm{kg})$ on day of test (DOT) was calculated for each animal $(\mathrm{BW}=\mu+\mathrm{bDOT}+\mathrm{e})$, where $\mathrm{b}$ is the regression coefficient (i.e., the growth rate; $\mathrm{kg} / \mathrm{d}$ ). Average DMI over the measurement period was determined as the mean of all daily DMI.

Calculation of Residual Feed Intake. Residual feed intake was calculated for each cohort of heifers separately. The RFI is most commonly calculated as 
the difference between actual DMI and predicted DMI. Predicted DMI is determined by phenotypic regression of actual DMI on measures of production and BW over the measurement period.

$$
\begin{aligned}
\mathrm{RFI} & =\mathrm{DMI}-(\mu+\mathrm{BW}+\mathrm{BW} \Delta \\
& \left.+ \text { farm }+ \text { age }+\mathrm{age}^{2}\right),
\end{aligned}
$$

where $\mu=$ the overall mean effect, $\mathrm{BW}=$ body weight at the midpoint, $\mathrm{BW} \Delta=$ growth rate, farm $=$ farm where heifers were sourced from, and age $=$ heifer age (in days). Farm was included to account for the variation observed in the farm effect for DMI and growth rate (Figure 2). As RFI was used to make decisions on which calves to purchase for future research, failure to remove these effects would result in biased RFI estimates. Effects of heifer age, and age-squared $\left(\right.$ age $\left.^{2}\right)$ were also accounted for because they had a significant effect. The effect of pen was not significant so was not included, probably because in most cases it was confounded with farm. Although it may have been useful to include the effects of height and BCS in our RFI model to account for body composition, these data were not collected in the study.

Two weeks before the end of the feeding periods for cohorts 1 and 3 , a preliminary RFI was calculated to determine which calves would be retained for future research. For both cohorts, calves were ranked based on their RFI, and the 30 highest- and 30 lowest-ranked animals that were also available for purchasing were kept for future research. The remaining calves were returned to their farm of origin once the feeding period had ended.

To help understand the mechanism responsible for the differences between high and low RFI animals, data from the $10 \%$ highest- and $10 \%$ lowest-ranked RFI calves from each cohort were pooled and Student's $t$-tests were performed on DMI, BW, growth rate, and age variables.

Heritability Calculation. The model used to estimate variance components of RFI, DMI, BW $\Delta$, and $\mathrm{BW}$, all averaged over the trial period, was

$$
\begin{aligned}
y_{i j k l m} & =\mu+\text { sire_breed }_{i}+\text { farm_cohort }_{j} \\
& +b_{1} \text { age }_{j k l m}+\text { animal }_{l}+e_{i j k l m},
\end{aligned}
$$

where $\mu$ is the overall mean; sire_breed ${ }_{i}$ is the effect of the $i$ th breed of sire (Holstein or Jersey); farm_cohort is the effect of the $j$ th farm cohort; $b_{1}$ age $i_{i j k l m}$ is the linear regression on age of the animal at the start of the experiment; animal $l_{l}$ is the random additive genetic effect of the $l$ th animal, and $e_{i j k l m}$ is the error term.

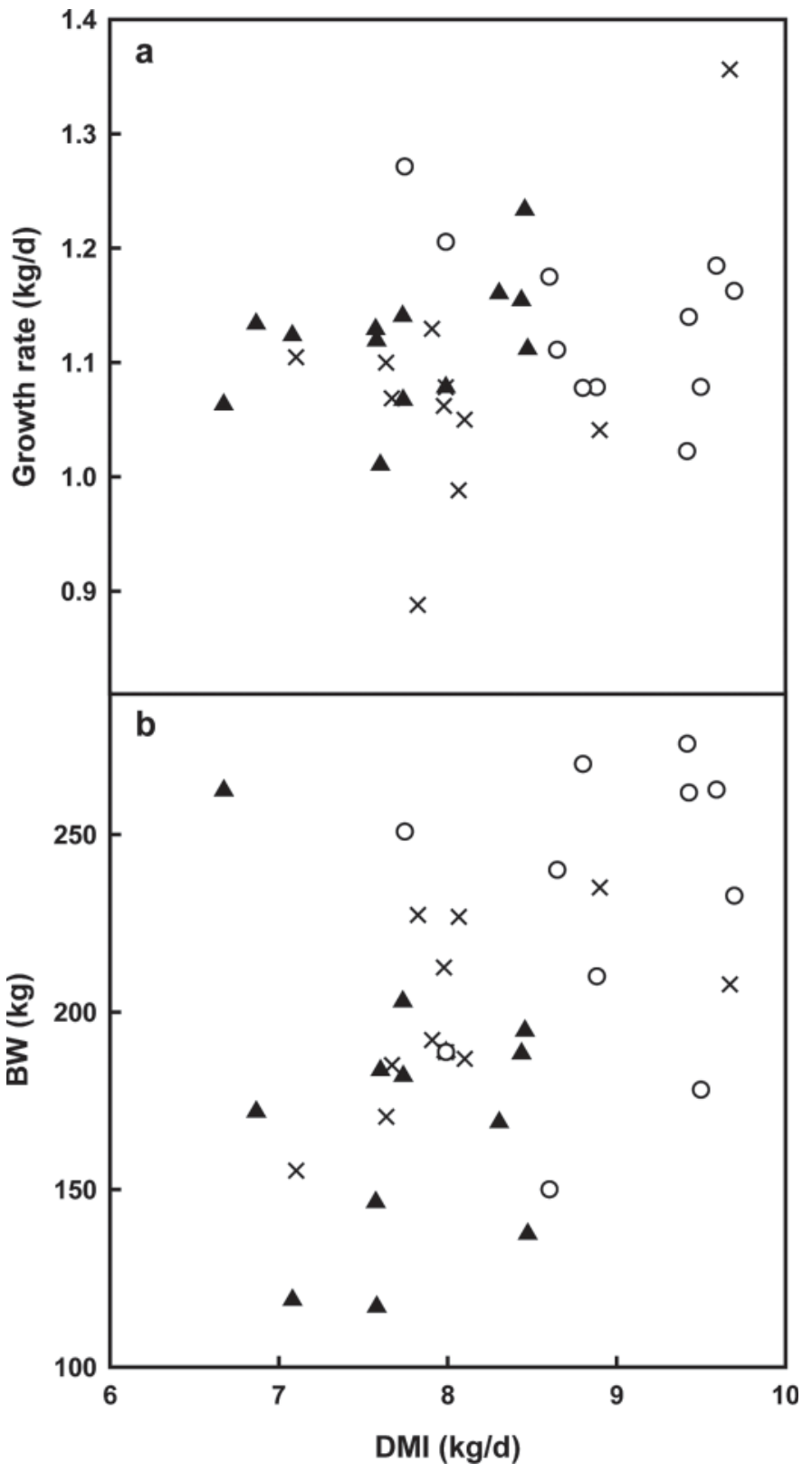

Figure 2. Farm effects for (a) growth rate and (b) BW plotted against average daily DMI. Cohort $1(\mathrm{x})$, Cohort $2(\boldsymbol{\Delta})$, Cohort $3(\mathrm{O})$.

Alternative models that included either a quadratic effect of age or the effect of calves being treated for illness throughout the trial were explored using ASReml (Gilmour et al., 2006). Neither of these effects was significant for any of the traits and, therefore, these effects were not considered for the rest of the analysis.

\section{RESULTS}

A summary of calf characteristics, differences in the feed offered and the intakes, growth rates, and efficien- 
Table 2. Characteristics (average \pm SE) of the $10 \%$ of calves with lowest (most efficient) and highest (least efficient) residual feed intake (RFI) rankings. The $P$-values were determined using Student's $t$-tests

\begin{tabular}{lccc}
\hline Item & Lowest $10 \%$ & Highest $10 \%$ & $P$-value \\
\hline RFI $(\mathrm{kg}$ of DM/d) & $-0.73( \pm 0.02)$ & $0.78( \pm 0.03)$ & \\
DMI $(\mathrm{kg} / \mathrm{d})$ & $7.6( \pm 0.14)$ & $9.3( \pm 0.14)$ & $* * *$ \\
Age $(\mathrm{d})$ & $222( \pm 2.1)$ & $224( \pm 2.0)$ & $\mathrm{NS}$ \\
BW $(\mathrm{kg})$ & $207( \pm 5.3)$ & $213( \pm 4.3)$ & $\mathrm{NS}$ \\
Growth rate $(\mathrm{kg} / \mathrm{d})$ & $1.08( \pm 0.02)$ & $1.09( \pm 0.02)$ & $\mathrm{NS}$ \\
Time spent in feeders $(\mathrm{min} / \mathrm{d})$ & $148( \pm 0.9)$ & $149( \pm 0.7)$ & $\mathrm{NS}$ \\
Intake rate $(\mathrm{g} / \mathrm{min})$ & $61( \pm 2.1)$ & $72( \pm 1.7)$ & $* * *$ \\
\hline
\end{tabular}

$* * * P<0.001$.

cies observed for each cohort are presented in Table 1. The $10 \%$ of calves with the highest RFI ranking from each cohort consumed $1.7 \mathrm{~kg}$ of DM more feed each day for the same level of weight gain than the $10 \%$ of calves with the lowest RFI ranking from each cohort (Table 2 ). The average RFI of these most efficient and least efficient groups of calves were $-0.73 \mathrm{~kg}$ of $\mathrm{DM} / \mathrm{d}$ and $0.78 \mathrm{~kg}$ of $\mathrm{DM} / \mathrm{d}$, respectively. Other characteristics were also investigated for these extreme RFI groups. The mean DMI and intake rate of the high and low RFI groups were statistically different, whereas BW, growth rate, age, and time spent feeding did not differ between the 2 groups (Table 2).

The R-squared statistics describing the goodness of fit of the regression of BW on DOT for each calf were high and averaged (mean $\pm \mathrm{SD}$ ) $0.97 \pm 0.029$ (Figure $3)$.

A histogram of RFI for all calves (Figure 4) shows RFI is normally distributed in the population of calves tested. Similarly, the histograms of growth rates, intakes, and BW, which are explanatory terms in the model, are also normally distributed (Figure 4).

On a plot of predicted feed intake (DMI + RFI) versus actual intake of all of the calves (Figure 5), the more efficient (low-RFI) calves are shown above the

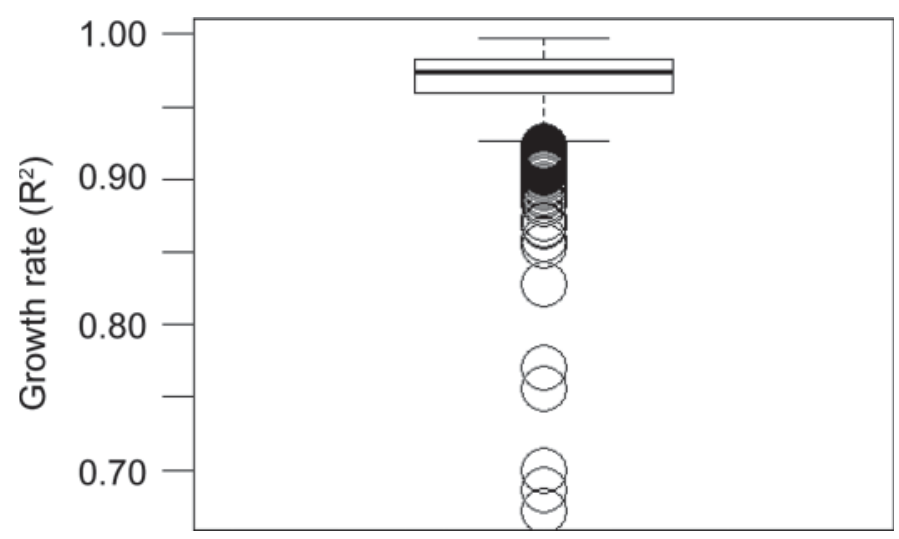

Figure 3. Distribution of $\mathrm{R}^{2}$ statistics for regression of $\mathrm{BW}$ against day of test for each calf. regression line, whereas the less efficient (high-RFI) calves are below the regression line. The $10 \%$ of calves with the highest and $10 \%$ with the lowest RFI rankings from each cohort are also highlighted.

The heritability estimate of RFI was $0.27( \pm 0.12)$. The heritability estimates of RFI and its component traits and the variance components are shown in Table 3.

\section{DISCUSSION}

The variation in RFI recorded in each cohort and in all cohorts together for the genetic analysis suggests a significant degree of variation among dairy heifers for this trait. The observed phenotypic standard deviation of $0.43 \mathrm{~kg}$ of DM/d for RFI was equivalent to $5 \%$ of average daily intake. This is lower than the standard deviation for RFI reported in several beef cattle studies (Table 4), but is higher than that reported by Robinson and Oddy (2004) who also suggested their RFI standard deviation of $0.37 \mathrm{~kg}$ of $\mathrm{DM} / \mathrm{d}$ represented useful variation to enable feed efficiency to be improved. The standard deviation reported in the dairy cattle studies given in Table 4 are variable due to the small numbers of animals tested and variation in the age and physiological state at test. Obviously, in young growing heifers the variation in RFI will be less than in mature animals. The most comparable study to ours was that of Korver et al. (1991), as this included growing heifers, and their standard deviation for RFI was $0.52 \mathrm{~kg}$ of $\mathrm{DM} / \mathrm{d}$. The difference in feed consumed between the top and bottom $10 \%$ of calves in our study was $1.6 \mathrm{~kg}$ of $\mathrm{DM} / \mathrm{d}$. If it is assumed that feed is worth $\$ 250 / \mathrm{t}$, this difference is worth $\$ 146 /$ calf per year. Herd et al. (2009) reported that in beef cattle, high-efficiency bred steers ate almost $1 \mathrm{~kg}$ of DM/d less over a 251-d period than low-efficiency bred steers.

The heritability of RFI $( \pm \mathrm{SE})$ was 0.27 (0.12), which is comparable to other studies reported in the literature. For example, in 377 lactating dairy cows in Scotland, the heritability of RFI was estimated to be 0.32 (Veerkamp et al., 1995) and in a larger study of around 
A)

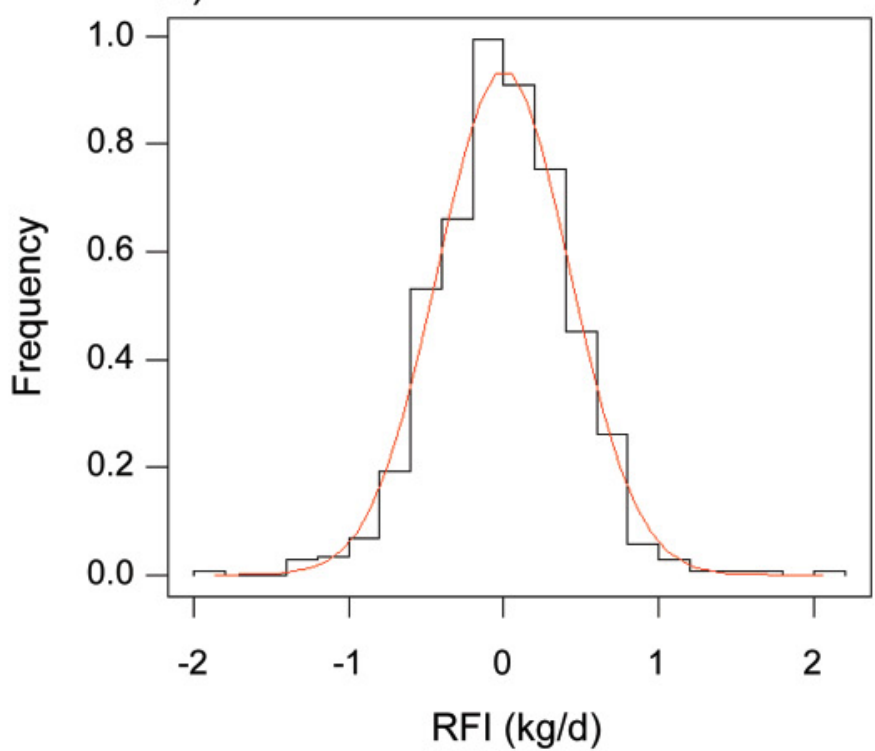

C)

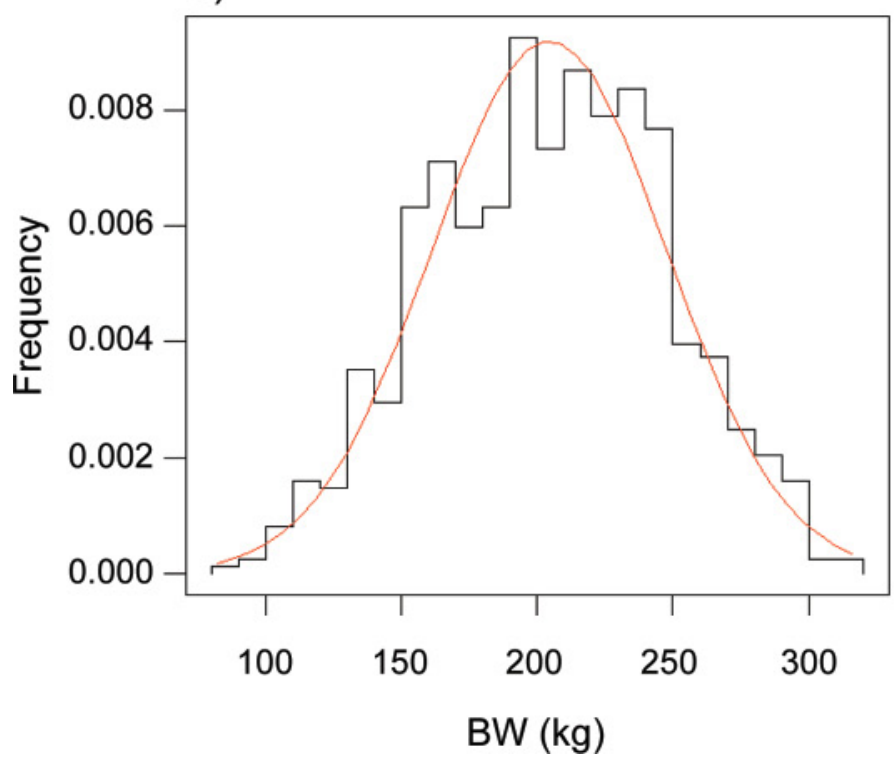

B)

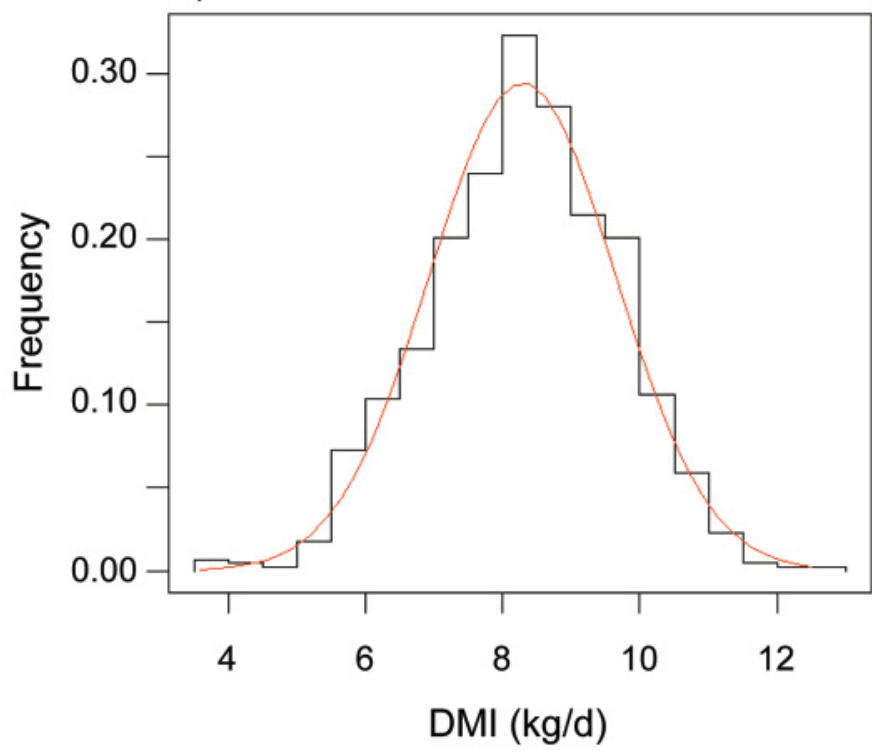

D)

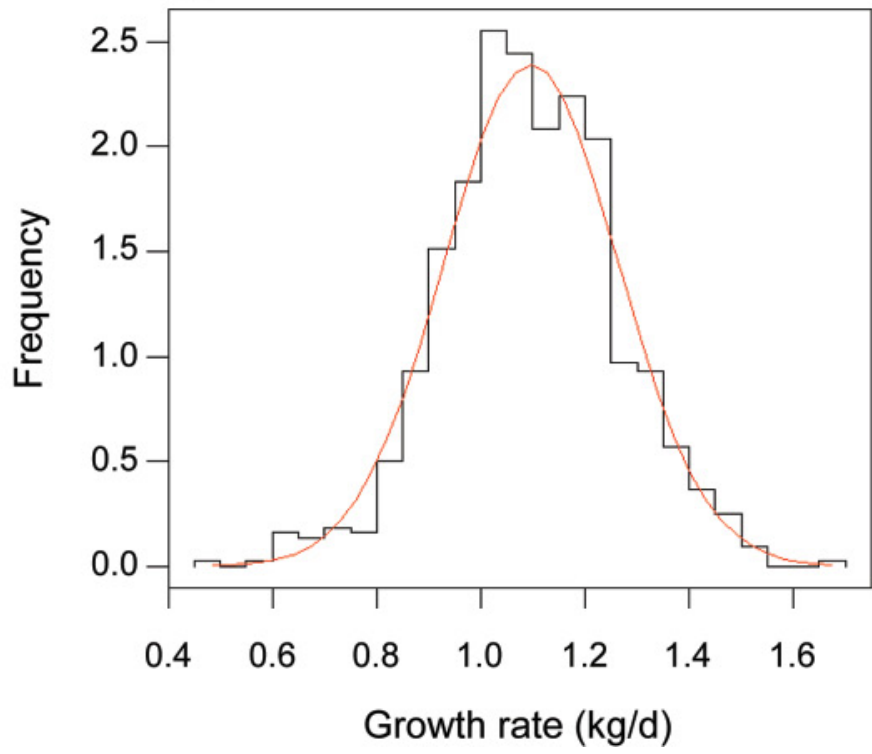

Figure 4. Distributions of (A) residual feed intake (RFI), (B) DMI, (C) BW, and (D) growth rate of all calves with normal distribution expectations (smooth line). Color version available in online PDF.

1,300 growing Charolais bulls, the heritability of RFI was $0.43( \pm 0.04)$ (Arthur et al., 2001b). Differences in heritability estimates can be attributed largely to differences in sample size. But in the present study and elsewhere it appears sufficient genetic variation in RFI exists to enable this trait to be considered as a candidate for future dairy selection indexes; that is, provided its associated economic value is sufficiently large for the RFI to have a noticeable effect on sire rankings when included in an index of overall economic merit.
Before RFI can be considered as a candidate trait for a selection index, however, it is essential to ensure that no unfavorable consequences exist of selecting for RFI. The principal calculation of RFI and energy balance is the same, as both traits are calculated from feed intake adjusted for energy requirements (Veerkamp, 2002). In cattle, genetically negative energy balance has been demonstrated to result in lower fertility (de Vries and Veerkamp, 2000; Banos et al., 2004; Pryce et al., 2004). To ensure the calculation of RFI is different from en- 
Table 3. Heritabilities (average $\pm \mathrm{SE}$ ) and genetic and phenotypic variances of residual feed intake (RFI) and its component traits (BW, DMI, and growth rate)

\begin{tabular}{lccc}
\hline Trait & Heritability & $\begin{array}{c}\text { Genetic } \\
\text { variance }\end{array}$ & $\begin{array}{c}\text { Phenotypic } \\
\text { variance }\end{array}$ \\
\hline RFI $(\mathrm{kg}$ of DM/d) & $0.27( \pm 0.12)$ & $0.051( \pm 0.023)$ & $0.19( \pm 0.01)$ \\
BW $(\mathrm{kg})$ & $0.32( \pm 0.12)$ & $151.3( \pm 61.4)$ & $479.6( \pm 24.7)$ \\
DMI $(\mathrm{kg})$ & $0.17( \pm 0.10)$ & $0.12( \pm 0.07)$ & $0.73( \pm 0.36)$ \\
Growth rate $(\mathrm{kg} / \mathrm{d})$ & $0.22( \pm 0.10)$ & $0.0040( \pm 0.0019)$ & $0.018( \pm 0.0009)$ \\
\hline
\end{tabular}

ergy balance, BCS and BW loss in early lactation are required to be properly accounted for in the calculation of RFI; otherwise, a risk exists that selection for low RFI could result in selection of animals that mobilize more body condition (greater negative energy balance), with concomitant negative effects on fertility. Evidence from beef cattle suggests that females selected for low RFI calve later than those selected for high RFI; however, the later calving did not affect pregnancy and calving rates (Arthur et al., 2005; Basarab et al., 2007; Donoghue et al., 2011). In the study by Basarab et al. (2007), cows that produced efficient calves (low RFI) were in better body fatness (as indicated by backfat thickness) throughout their lifetime than cows that produced high-RFI progeny. Arthur et al. (2005), on the other hand, reported that in 3 of the $4 \mathrm{yr}$ tested, low-RFI cows had lower rib fat depths at the start of the mating season compared with high-RFI cows, whereas Donoghue et al. (2011) found that low-RFI females had lower fat depth at most measurement times. Donoghue et al. (2011) also demonstrated a trend for low-RFI heifers to attain puberty at a slightly lower age than high-RFI heifers which affected the date of their first calving. This later calving date was then maintained in subsequent calvings. These results highlight the importance of obtaining genetic correlations between RFI and health and fertility traits in dairy cattle to determine if this risk is real.
The measurement of RFI takes place during a relatively narrow window of the animals' growing period. Studies with beef cattle have shown that results obtained during post-weaning periods appear to carry over into later stages of the growing period. For example, selection based on RFI measured during short periods post-weaning (e.g., for $70 \mathrm{~d}$ at 8 to $10 \mathrm{mo}$ of age) results in improved efficiency of cattle during finishing in feedlots (e.g., from 13 to 20 mo of age; Herd et al., 2009). Whether this holds true for dairy cattle, and selection for RFI based on growth when young results in improved efficiency during lactation when mature remains to be seen, and is something that will be tested with the heifers retained for future research.

Many digestive and metabolic processes exist that can affect feed efficiency in cattle - feed intake and level of production, behavior and eating patterns, digestion and digestibility, and utilization of absorbed nutrients (Waghorn and Dewhurst, 2007; Herd and Arthur, 2009). The effects of feeding level and type of feed on efficiency are not well understood. Feeding level is usually variable over a season in a pasture-based system. It is unknown if the efficiency ranking of a cow will alter if she is at a restricted level of intake rather than ad libitum intake. Some evidence for consistency of efficiency under different feeding levels has been reported by Herd et al. (2005). When steers born to parents selected for high and low post-weaning RFI

Table 4. Heritabilities $\left(\mathrm{h}^{2}\right)$ and standard deviations for residual feed intake (RFI) and the standard deviation expressed as a percentage of feed intake (FI) in beef and dairy cattle from studies reported in the literature

\begin{tabular}{|c|c|c|c|c|c|}
\hline Reference & Type of animals tested & No. & $\mathrm{h}^{2}$ & $\begin{array}{c}\text { RFI SD } \\
(\mathrm{kg} / \mathrm{d})\end{array}$ & $\% \mathrm{FI}$ \\
\hline Korver et al. (1991) & Dairy heifers, growing & 417 & 0.22 & 0.52 & 7.6 \\
\hline van Arendonk et al. (1991) & Dairy heifers, lactating & 360 & 0.19 & 0.7 & 4.7 \\
\hline \multirow[t]{2}{*}{ Svendsen et al. (1993) } & Dual-purpose cows, early lactation & 353 & 0.00 & 0.81 & - \\
\hline & Dual-purpose cows, midlactation & 353 & 0.02 & 0.54 & - \\
\hline Arthur et al. (2001a) & Angus cattle, post-weaning & 1,177 & 0.39 & 0.74 & 7.7 \\
\hline Wang et al. (2006) & Hybrid beef steers & 456 & & 0.79 & 8.5 \\
\hline Hoque et al. (2007) & Japanese black bulls & 740 & 0.33 & 0.84 & 9.1 \\
\hline Nkrumah et al. (2007) & Hybrid beef steers & 464 & 0.21 & 0.88 & 8.4 \\
\hline
\end{tabular}




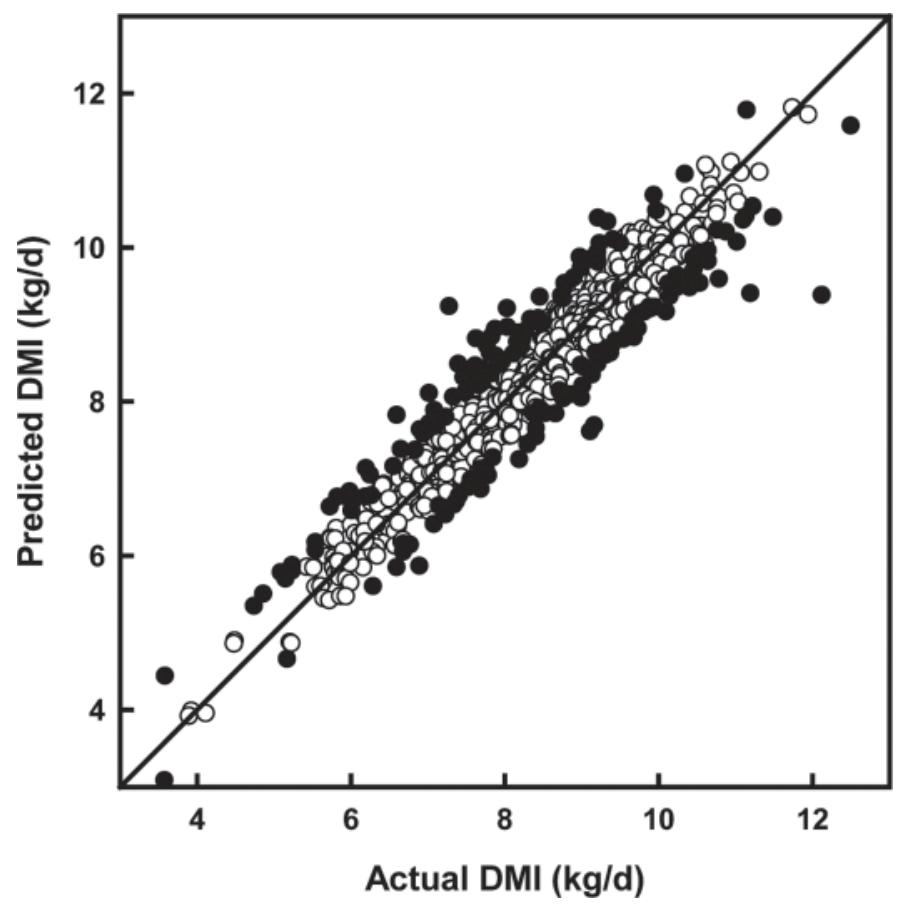

Figure 5. Predicted feed intake versus actual feed intake for all calves tested. Calves above the line are more efficient than animals below the line. Solid dots indicate the top and bottom $10 \%$ of animals from each cohort with respect to residual feed intake.

grazed pasture at intakes that limited growth rate, the low-RFI bred steers grew at a faster rate. The diet used during our initial calf screening was 100\% forage; however, most cows in a pasture-based production system receive grain-based supplements at some time of the year. Some evidence with beef heifers suggests that feed efficiency rankings can vary with low- and high-energydensity diets (Christopher and Marston, 2007). Redden et al., (2011) also found no correlation between RFI measured in 9-mo-old sheep on a pelleted grower diet (grain and forage) and the same sheep at 13-mo old on a forage-only maintenance diet.

The lower rate of intake observed in the top $10 \%$ compared with the bottom $10 \%$ RFI animals in this experiment is consistent with some studies with beef cattle (Bingham et al., 2009; Kelly et al., 2010; Montanholi et al., 2010). Instances, however, also exist where the eating rate did not differ between low- and high-RFI cattle (Dobos and Herd, 2008; Golden et al., 2008). A study on the energy cost of eating in cattle (Adam et al., 1984) concluded that rate of ingestion and meal duration were key factors in determining the energy cost of eating in cattle, and that the energy cost is more a function of time spent eating than of the amount of food ingested. Given that time spent in feeders did not differ between the $10 \%$ highest and lowest RFI heifers, then energy costs of eating may have been the same for both groups. On the other hand, ingestive behavior, which includes intake rate, has been linked to rumen function and digestion (Demment and Greenwood, 1988), and has the potential to affect feed efficiency (Waghorn and Dewhurst, 2007). It is well known that increasing the level of intake decreases overall digestibility of the feed eaten (Standing Committee on Agriculture, 1990), but the link between intake rate and digestibility is not clear. Much research has been carried out under both grazing and TMR systems to determine the factors that drive intake and intake rate (Ungar, 1996; Tafaj et al., 2007; Abrahamse et al., 2008). This has enabled the creation of feeding environments at grazing and in feed bunks that provide high genetic merit cows with the opportunities to achieve the high intakes they require to meet their large energy demands, although more research is needed to improve our understanding of the association between feeding behavior and feed efficiency.

Energy utilization studies with pigs divergently selected for RFI, found that high-RFI pigs were energetically less efficient due to their greater heat production related to physical activity and basal metabolic rate (Barea et al., 2010). The thermic effect of feeding, as a percentage of ME intake, was the same for both high- and low-RFI pigs, however (Barea et al., 2010). Similarly, preliminary observations in a small number of beef heifers divergently selected for RFI, indicate that energy expenditure per unit of ME intake did not differ between the selection lines, but evidence was found that high-RFI (less efficient) beef animals retained more energy in fat (Lines et al., 2009). Several studies with beef cattle have indicated potential for small decreases in carcass fatness and rate of subcutaneous fat gain, and a slight improvement in lean meat yield following selection for low RFI (Richardson et al., 2001; Basarab et al., 2003; Nkrumah et al., 2007). Basarab et al. (2007) also found that RFI was positively related to measures of body fat but these relationships disappeared when RFI was adjusted for backfat thickness. This may not necessarily be the case in dairy cattle, however, as selection objectives have been very different, principally selection for milk production, with associated reliance on body tissue mobilization to sustain early lactation, in particular. Indicators of body type (e.g., body composition and height), were not measured in our heifers during the RFI measurement period, so it is unknown if differences existed in the composition of the weight gain in the $10 \%$ highest- and lowest-RFI heifers. Future research with the retained heifers will include these measurements using BCS as a proxy for body composition. The full consequences of selection for RFI need to be understood, as selection for RFI should not impinge upon the normal biological process- 
es a commercial dairy cow is expected to perform, such as calving every year. A need may also exist to examine if RFI is the most appropriate measure of efficiency for lactating dairy cows (Coleman et al., 2010).

\section{CONCLUSIONS}

In conclusion, significant variation in RFI does exist in dairy heifers, and the magnitude of this variation is large enough to be economically important. A primary focus of future research should be to ensure that calves that are efficient at converting feed energy for maintenance and growth also become efficient at converting feed energy to milk. It will also be necessary to identify the consequences of selection for RFI on other traits (especially fertility and other fitness traits) and if any interactions of RFI with feeding level exist. Our understanding of the association between feeding behavior and feed efficiency also requires improvement.

\section{ACKNOWLEDGMENTS}

The authors thank Taffy Phillips (DPI-Rutherglen, Victoria, Australia) and Marg Jenkin (DPI-Tatura, Victoria, Australia) for their technical expertise in the day-to-day running of the Rutherglen feed intake facility, the management of the calves, and data collation. The skilled assistance of other farm staff is also acknowledged. Melbourne University (Australia) master's student, Zibei Lei, is acknowledged for the initial analysis of feeding behavior data from cohort 1. Funding for this research was provided by Gardiner Foundation (Victoria, Australia) and Department of Primary Industries (Victoria, Australia). The authors thank Peter Moate (DPI-Ellinbank, Victoria, Australia) for his helpful comments during the preparation of this manuscript.

\section{REFERENCES}

Abrahamse, P. A., B. Vlaeminck, S. Tamminga, and J. Dijkstra. 2008 The effect of silage and concentrate type on intake behavior, rumen function, and milk production in dairy cows in early and late lactation. J. Dairy Sci. 91:4778-4792.

Adam, I., B. A. Young, A. M. Nicol, and A. A. Degen. 1984. Energy cost of eating in cattle given diets of different form. Anim. Prod. $38: 53-56$

Archer, J. A., P. F. Arthur, R. M. Herd, P. F. Parnell, and W. S. Pitchford. 1997. Optimum postweaning test for measurement of growth rate, feed intake, and feed efficiency in British breed cattle. J. Anim. Sci. 75:2024-2032.

Archer, J. A., E. C. Richardson, R. M. Herd, and P. F. Arthur. 1999. Potential for selection to improve efficiency of feed use in beef cattle: A review. Aust. J. Agric. Res. 50:147-161.

Arthur, P. F., J. A. Archer, and R. M. Herd. 2004. Feed intake and efficiency in beef cattle: Overview of recent Australian research and challenges for the future. Aust. J. Exp. Agric. 44:361-369.

Arthur, P. F., J. A. Archer, D. J. Johnston, R. M. Herd, E. C. Richardson, and P. F. Parnell. 2001a. Genetic and phenotypic variance and covariance components for feed intake, feed efficiency, and other postweaning traits in Angus cattle. J. Anim. Sci. 79:28052811.

Arthur, P. F., R. M. Herd, J. F. Wilkins, and J. A. Archer. 2005. Maternal productivity of Angus cows divergently selected for postweaning residual feed intake. Aust. J. Exp. Agric. 45:985-993.

Arthur, P. F., G. Renand, and D. Krauss. 2001b. Genetic and phenotypic relationships among different measures of growth and feed efficiency in young Charolais bulls. Livest. Prod. Sci. 68:131-139.

Banos, G., S. Brotherstone, and M. P. Coffey. 2004. Evaluation of body condition scores measured throughout lactation as an indicator of fertility in dairy cows. J. Dairy Sci. 87:2669-2676.

Barea, R., S. Dubois, H. Gilbert, P. Sellier, J. van Milgen, and J. Noblet. 2010. Energy utilization in pigs selected for high and low residual feed intake. J. Anim. Sci. 88:2062-2072.

Basarab, J. A., D. McCartney, E. K. Okine, and V. S. Baron. 2007. Relationships between progeny residual feed intake and dam productivity traits. Can. J. Anim. Sci. 87:489-502.

Basarab, J. A., M. A. Price, J. L. Aalhus, E. K. Okine, W. M. Snelling, and K. L. Lyle. 2003. Residual feed intake and body composition in young growing cattle. Can. J. Anim. Sci. 83:189-204.

Beever, D. E., and P. T. Doyle. 2007. Feed conversion efficiency as a key determinant of dairy herd performance: A review. Aust. J. Exp. Agric. 47:645-657.

Bingham, G. M., T. H. Friend, P. A. Lancaster, and G. E. Carstens. 2009. Relationship between feeding behavior and residual feed intake in growing Brangus heifers. J. Anim. Sci. 87:2685-2689.

Christopher, J. A., and T. T. Marston. 2007. Comparison of feed efficiency rankings of heifers fed low and high density diets. Beef Cattle Research. Report of Progress 978. Kansas State University, Manhattan.

Coleman, J., D. P. Berry, K. M. Pierce, A. Brennan, and B. Horan. 2010. Dry matter intake and feed efficiency profiles of 3 genotypes of Holstein-Friesian within pasture-based systems of milk production. J. Dairy Sci. 93:4318-4331.

de Vries, M. J., and R. F. Veerkamp. 2000. Energy balance of dairy cattle in relation to milk production variables and fertility. J. Dairy Sci. 83:62-69.

Demment, M. W., and G. B. Greenwood. 1988. Forage ingestion: Effects of sward characteristics and body size. J. Anim. Sci. 66:2380-2392.

Dobos, R., and R. Herd. 2008. Spectral analysis of feeding patterns of steers divergent in residual feed intake. Aust. J. Exp. Agric. 48:843-846.

Donoghue, K. A., P. F. Arthur, J. F. Wilkins, and R. M. Herd. 2011. Onset of puberty and early-life reproduction in Angus females divergently selected for post-weaning residual feed intake. Anim. Prod. Sci. 51:183-190.

Gilmour, A. R., B. J. Gogel, B. R. Cullis, and R. Thompson. 2006. ASReml User Guide Release 2.0. VSN International Ltd., Hemel Hempstead, UK.

Golden, J. W., M. S. Kerley, and W. H. Kolath. 2008. The relationship of feeding behavior to residual feed intake in crossbred Angus steers fed traditional and no-roughage diets. J. Anim. Sci. $86: 180-186$.

Hegarty, R. S., J. P. Goopy, R. M. Herd, and B. McCorkell. 2007. Cattle selected for lower residual feed intake have reduced daily methane production. J. Anim. Sci. 85:1479-1486.

Herd, R. M., and P. F. Arthur. 2009. Physiological basis for residual feed intake. J. Anim. Sci. 87(E. Suppl.):E64-E71.

Herd, R. M., P. F. Arthur, and J. A. Archer. 2005. When pastures limit growth rate of steers those bred for low residual feed intake grow faster. Pages 330-333 in Proc. 16th Conf. Assoc. Advance. Anim. Breed. Genet., Noosa Lakes, Queensland, Australia.

Herd, R. M., S. Piper, J. M. Thompson, P. F. Arthur, B. McCorkell, and K. C. P. Dibley. 2009. Benefits of genetic superiority in residual feed intake in a large commercial feedlot. Pages 476-479 in Proc. 18th Conf. Assoc. Advance. Anim. Breed. Genet., Barossa Valley, South Australia, Australia.

Ho, C., R. Nesseler, P. Doyle, and B. Malcolm. 2005. Future dairy farming systems in irrigation regions. Aust. Farm Bus. Manage. J. $2: 59-68$. 
Hoque, M. A., P. F. Arthur, K. Hiramoto, A. R. Gilmour, and T. Oikawa. 2007. Variance components due to direct genetic, maternal genetic and permanent environmental effect for growth and feed efficiency traits in young male Japanese Black cattle. J. Anim. Breed. Genet. 124:102-107.

Kelly, A. K., M. McGee, D. H. Crews Jr., A. G. Fahey, A. R. Wylie, and D. A. Kenny. 2010. Effect of divergence in residual feed intake on feeding behavior, blood metabolic variables, and body composition traits in growing beef heifers. J. Anim. Sci. 88:109-123.

Kennedy, B. W., J. H. van der Werf, and T. H. Meuwissen. 1993. Genetic and statistical properties of residual feed intake. J. Anim. Sci. 71:3239-3250.

Koch, R. M., L. A. Swiger, D. Chambers, and K. E. Gregory. 1963. Efficiency of feed use in beef cattle. J. Anim. Sci. 22:486-494.

Korver, S., E. A. M. van Eekelen, H. Vos, G. J. Nieuwhof, and J. A. M. van Arendonk. 1991. Genetic parameters for feed intake and feed efficiency in growing dairy heifers. Livest. Prod. Sci. 29:49-59.

Lines, D. S., M. L. Wolcott, W. S. Pitchford, C. D. K. Bottema, R. M. Herd, and V. H. Oddy. 2009. Some consequences of selection for residual feed intake in beef cattle. Pages 604-607 in Proc. 18th Conf. Assoc. Advance. Anim. Breed. Genet., Barossa Valley, South Australia, Australia.

McNaughton, L. R., and J. E. Pryce. 2007. Metabolic feed efficiency - opportunities for selection in dairy cows. Proc. N.Z. Soc. Anim. Prod. 67:392-398.

Montanholi, Y. R., K. C. Swanson, R. Palme, F. S. Schenkel, B. W. McBride, D. Lu, and S. P. Miller. 2010. Assessing feed efficiency in beef steers through feeding behavior, infrared thermography and glucocorticoids. Animal 4:692-701.

Ngwerume, F., and I. L. Mao. 1992. Estimation of residual energy intake for lactating cows using an animal model. J. Dairy Sci. $75: 2283-2287$.

Nieuwhof, G. J., J. A. M. van Arendonk, H. Vos, and S. Korver. 1992. Genetic relationships between feed intake, efficiency and production traits in growing bulls, growing heifers and lactating heifers. Livest. Prod. Sci. 32:189-202.

Nkrumah, J. D., J. A. Basarab, M. A. Price, E. K. Okine, A. Ammoura, S. Guercio, C. Hanson, C. Li, B. Benkel, B. Murdoch, and S. S. Moore. 2004. Different measures of energetic efficiency and their phenotypic relationships with growth, feed intake, and ultrasound and carcass merit in hybrid cattle. J. Anim. Sci. 82:2451-2459.

Nkrumah, J. D., J. A. Basarab, Z. Wang, C. Li, M. A. Price, E. K. Okine, D. H. Crews Jr., and S. S. Moore. 2007. Genetic and phenotypic relationships of feed intake and measures of efficiency with growth and carcass merit of beef cattle. J. Anim. Sci. 85:27112720 .

Pryce, J. E., M. D. Royal, P. C. Garnsworthy, and I. L. Mao. 2004. Fertility in the high producing dairy cow. Livest. Prod. Sci. $86: 125-135$.

Pryce, J. E., J. H. J. van der Werf, M. Haile-Mariam, B. Malcolm, and M. E. Goddard. 2009. Updated index weights for the Australian Profit Ranking in dairy. Pages 143-146 in Proc. of 18th Conf. Aust. Assoc. Anim. Breed. Genet., Barossa Valley, South Australia, Australia.
Redden, R. R., L. M. M. Surber, B. L. Roeder, B. M. Nichols, J. A. Paterson, and R. W. Knott. 2011. Residual feed efficiency established in a post-weaning growth test may not result in more efficient ewes on the range. Small Rumin. Res. 96:155-159. doi:10.1016/j. smallrumres.2010.12.007.

Richardson, E. C., R. M. Herd, V. H. Oddy, J. M. Thompson, J. H. Archer, and P. F. Arthur. 2001. Body composition and implications for heat production of Angus steer progeny of parents selected for and against residual feed intake. Aust. J. Exp. Agric. 41:1065-1072.

Robinson, D. L., and V. H. Oddy. 2004. Genetic parameters for feed efficiency, fatness, muscle area and feeding behaviour of feedlot finished beef cattle. Livest. Prod. Sci. 90:255-270.

Standing Committee on Agriculture. 1990. Feeding standards for Australian livestock. Commonwealth Scientific and Industrial Research Organisation (CSIRO), East Melbourne, Victoria, Australia.

Svendsen, M., P. Skipenes, and I. L. Mao. 1993. Genetic parameters in the feed conversion complex of primiparous cows in the first two trimesters. J. Anim. Sci. 71:1721-1729.

Tafaj, M., Q. Zebeli, Ch. Baes, H. Steingass, and W. Drochner. 2007. A meta-analysis examining effects of particle size of total mixed rations on intake, rumen digestion and milk production in highyielding dairy cows in early lactation. Anim. Feed Sci. Technol. 138:137-161.

Ungar, E. D. 1996. Ingestive behaviour. Pages 185-218 in The Ecology and Management of Grazing Systems. J. Hodgson and A. W. Illius, ed. CAB International, Wallingford, Oxon, UK.

Van Arendonk, J. A. M., G. J. Nieuwhof, H. Vos, and S. Korver. 1991. Genetic aspects of feed intake and efficiency in lactating dairy heifers. Livest. Prod. Sci. 29:263-275.

van der Westhuizen, R. R., J. van der Westhuizen, and S. J. Schoeman. 2004. Genetic variance components for residual feed intake and feed conversion ratio and their correlations with other production traits in beef bulls. S. Afr. J. Anim. Sci. 34:257-264.

Veerkamp, R. F. 2002. Feed intake and energy balance in lactating animals. Proc. 7th World Congr. Gene. Appl. Livest. Prod. Montpellier, France. CD-ROM Session 10-01.

Veerkamp, R. F., and G. C. Emmans. 1995. Sources of genetic variation in energetic efficiency of dairy cows. Livest. Prod. Sci. 44:87-97.

Veerkamp, R. F., G. C. Emmans, A. R. Cromie, and G. Simm. 1995. Variance components for residual feed intake in dairy cows. Livest. Prod. Sci. 41:111-120.

Waghorn, G. C., and R. J. Dewhurst. 2007. Feed efficiency in cattle The contribution of rumen function. Pages 111-123 in Meeting the challenges for pasture-based dairying. Proc. Australasian Dairy Sci. Symp. Melbourne, Australia. National Dairy Alliance, Melbourne, Australia.

Wall, E., G. Simm, and D. Moran. 2010. Developing breeding schemes to assist mitigation of greenhouse gas emissions. Animal 4:366376.

Wang, Z., J. D. Nkrumah, C. Li, J. A. Basarab, L. A. Goonewardene, E. K. Okine, D. H. Crews Jr., and S. S. Moore. 2006. Test duration for growth, feed intake, and feed efficiency in beef cattle using the GrowSafe system. J. Anim. Sci. 84:2289-2298. 